\title{
A New Gender Revolution in China: Beyond the Resumption of a Historical Authenticity
}

\author{
Huai Bao
}

\begin{abstract}
This study examines the revival of the nandan tradition in jingju, the trends of gender transgression in popular media in Mainland China, and the relationship between the two of them. The "revival" of the historical "authenticity" and the increasing popularity of drag on mainstream media are both the product of consumer economy in the digital age and a growing awareness of the complexity of human nature.
\end{abstract}

Index Terms - Sexuality, gender, performance, media.

\section{INTRODUCTION}

Jingju, also known as Beijing Opera or Peking Opera, is the most representative form of xiqu-a collective term of Chinese indigenous theatrical forms. Historically, it had a primarily all-male cast with men playing female characters. These female impersonators are called "nandan." While nandan was banned in the People's Republic of China (PRC), particularly since the beginning of the Cultural Revolution (1966-1976), in the past few decades, there has been a vibrant revival (mostly unofficial) of nandan in jingju, accompanied by the mainstreaming of drag in Chinese popular media, oftentimes allegedly inspired by nandan in jingju. These phenomena not only reflect a lasting gendered aesthetic tradition in the Chinese cultural psychology, but also suggest a gender revolution occurring beyond a mere revival of an old art form.

\section{The RevivaL}

Elizabeth Wichmann-Walczak, who visits China regularly for jingju conferences as well as preparations for student jingju productions at the University of Hawaii at Monoa, observes that nandan performers in jingju "are increasing rapidly," and "more and more [nandan performers] are being trained" during the last one or two decades. Sun Peihong, an adjunct professor teaching at the National Academy of Chinese Theatre Art (NACTA) and the Central Academy of Drama (CAD), informed me during interviews in 2012 and 2014 that, while more and more nandan performers have been trained most unofficially, there were quite a few nandan performers hired by jingju companies, from the National Jingju Theatre (Guojia Jingju Yuan) in Beijing to local jingju companies in provinces outside of Beijing. Retired nandan performing artist Wen Ruhua (1947-) revealed in interviews that he was often visited by nandan performers or trainees at his Beijing residence soliciting advice on performance skills

Manuscript received March 21, 2016; revised July 21, 2016. This work was supported in part by the Social Sciences and Humanities Research Council in Canada.

Huai Bao is with University of Toronto, Canada (e-mail: hbao@sfu.ca). and technique. Among them was Liu Bing, a student at NACTA, whom I interviewed in person in 2012 and by phone in 2014. In fact, numerous news reports in China suggest that there have been many appeals from high-ranking cultural officials, theatre critics, professors of $x i q u$, and leading jingju performing artists for increased training of nandan and public performance by nandan performers of the young generation.

The return of nandan in jingju dovetails with a revolution of gender-alternative expressions that extends from theatrical practice into lived realities in contemporary Chinese society. The reasoning is based on two facts. Firstly, the revival has been taking place in an era when women are not kept off stage any more, and cross-gender acting is not compulsive. Secondly, there is no shortage of highly acclaimed and widely accepted performers who play roles of the same sex and thus no need to reaffirm patriarchal gender construction or reassert "historical authenticity." In the case of jingju, while cross-gender performance was a cultural and theatrical norm within the feudal patriarchal structures in the past, the revival may be interpreted as a transgressive phenomenon that challenges gender boundaries, and this has brought thoughts on gender complexity to the forefront. The theatre serves as the laboratory for gender-alternative expressions given its legitimate cross-gender tradition and patriarchal structure. Under the names of a "renaissance" of "historical authenticity," the revival of nandan is in fact a reflection of a growing revolution that questions gender boundaries and seeks to subvert social and cultural assignments to biological genders. Through the revival, we do not only see the return of a long lost tradition on the stage; we also see an arena where many individual cases gather narrating stories that advance our cognition of sexual desire, sexual orientation and gendered behaviours. In the revival of cross-gender performance in jingju, performers and spectators are negotiating a new gender politics and contesting "normalized" knowledges and disciplinary powers. It is neither a retrograde action against female empowerment on the stage nor a resumption of patriarchal oppression, since it advocates freedom of choosing role types and freedom of cross-gender expressions; rather, it presents advances in thought within a gender spectrum.

In the case of jingju, the revival of nandan also has politically critical meaning based on communist perceptions of genders, as the notion of "revival" here is set in a context opposed to the political ban since the founding of the PRC, especially during the Cultural Revolution. One reason was because cross-gender casting was construed as a backward, risqué feudal heritage, in that nandan in the "old society" was usually associated with homoerotic consumerism. Another reason was because cross-gender performance might have distorted the revolutionary heroic image in those modern 
model plays that served the proletarian class [1]. In theorizing the fear of losing the righteous revolutionary qualities I would use the term, "socialist femmophobia," in that male performers impersonating women or male characters played by female performers all impart anti-heroic feudal feminine qualities either to performers or characters. Hence, cross-gender performance disappeared from the stage in nearly all cities in the PRC. Song Changrong (1935-), the renowned nandan performing artist of the Xun school in the small city, Huaiyin, in Jiangsu province, was kept playing female roles in revolutionary model plays, but Song's case was very exceptional at the time.

The Cultural Revolution was ended right after Mao's death in 1976. With Deng Xiaoping assuming the reins of the government and bringing order out of chaos, classical jingju plays and former nandan performing artists were able to return to the stage, including Zhang Junqiu, Zhao Rongchen (1916-1996) and Mei Baojiu (1934-2016). Since xiqu schools and jingju troupes no longer officially trained nandan students after the founding of the PRC in 1949 [2], other than those former nandan performing artists who achieved recognition prior to 1949 , there were no newly trained nandan performers known to the public, until Wen Ruhua staged a customized newly written play, White Faced Gentleman (Bai mian liang jun). In this new play he demonstrated his superb dan technique and artifice by switching between the impersonation of a young man and a beautiful woman.

Of the many revival cases that I have investigated, the one about Wen Ruhua is the most time consuming, not only because the once-upon-a-time allegation that he was "the last nandan" needs much clarification, but also because, as a shrewd observer, a thinker and a self-developed queer theorist who has formed his own theory to make sense of himself and other nandan performers, he can always talk for hours on this subject matter.

White Faced Gentleman was created and first staged in the mid-1980s, starring Wen Ruhua, whose character in the play had to disguise himself as a woman. According to Wen himself, he was the first jingju performer who received official approval of his transfer from his assigned xiaosheng role category to his desired dan category, and White Faced Gentleman played a crucial role in this transition. Although by then such renowned nandan performers as Mei Baojiu had returned to the stage, and Zhang Junqiu was teaching at NACTA, it has been confirmed to me by a large group of jingju experts, artists and government officials from the Ministry of Culture and the Beijing Cultural Bureau that those who had established star status as a nandan performer prior to the Cultural Revolution could perform again, while there were no new nandan performers formally recognized. These star performers' return to the stage was the resumption of jobs that had been terminated during the Cultural Revolution, not the revival that I am addressing here.

I first met Wen at his guest lecture on the nandan art in Beijing in 1996, at the Lu Xun Academy of Liberal Arts ( $L u$ Xun wenxue yuan), a state-run institution founded in 1950 to train writers, literary critics, literary editors and translators.

Wen was admitted to the National School of Chinese Theatre Arts (Zhongguo xiqu xuexiao), the predecessor of NACTA, when he was eleven years old in 1958. He informed me that though his then desired role type was dan, he was assigned, along with a group of other fellow male students who aspired to study dan, to the role type of xiaosheng. Of all the other role categories and their subcategories, xiaosheng is the closest to dan, largely because both xiaosheng and dan require the use of falsetto voice for speech and singing. Xiaosheng performers have to sing in falsetto voice and speak in it as well with occasional breaks to represent the adolescent crack period. It has to be noted that although all role types share the same principles for bodily movements, such as roundness and the yin and yang diagram, as well as specific movements such as yunshou (cloud-hands). The movement yunshou is used between movements as the means of passage between states. In doing so, the body stands as axis and the arms move as if the performer were holding a ball in front him/her, and then extend to strike a pose. There are variations between role categories and subcategories "in verbal, melodic, percussive, and movement composition, and in performance technique" [3]. Since the xiaosheng role type usually portrays young gentlemen of scholarly bearing, its movements emphasize elegance and gentility and thus possesses some of the yin qualities of dan role.

Wen was not too disappointed as these two role categories were interchangeable in a sense because of the gendered similarity. In explaining this gendered similarity, I need to re-emphasize here that in ancient Chinese society ruled under the Confucian ideology and with a traditional aesthetic tendency favouring male femininity, a young scholar with refined qualities such delicacy and gentility was perceived as an ideal, while hypermasculinity in a man was considered to be coarse, barbaric and unattractive. In this sense, xiaosheng is always considered the role type closest to dan. Wen graduated in 1966, the year when the Cultural Revolution erupted. He became a playwright and director at the Comrades-in-Arms Jingju Company (Zhanyou jingju tuan), where he had not even the chance to perform in the xiaosheng role type because it was banned. Being multi-talented, he was most of the time composing and editing music scores for modern jingju plays, through which he seized the opportunity to study with Zhang Junqiu, the then best-known nandan performing artist and founder of his own style, known as the Zhang school. According to Wen, from 1976 till 1982 he did not have any chance to perform in the dan role, except that in 1978 he played the female lead, Tan Ji'er, in The Riverview Pavilion (Wang jiang ting), one of Zhang Junqiu's more representative works based on a Yuan dynasty play. Though performed on a small scale, this play was good enough to impress a distinguished member of the audience-the then renowned jingju playwright, Weng Ouhong (1908-1994), who had written about 100 jingju plays and who had written for a great number of jingju stars. In 1982, Wen transferred to the more prestigious Beijing Jingju Theatrical Company (Beijing jingju tuan), later renamed as Beijing Jingju Theatre. According to him in the 2012 interview, he and Weng Ouhong contemplated strategies to legitimize Wen's desired transfer to the dan role category. Weng Ouhong wrote for him a customized play based on a sub-story from one of the four great Chinese classical novels, Water Margin (Shui hu), a 14th century novel written in vernacular Chinese with the story set in the Song dynasty about how a group of 108 righteous outlaws gathered at the Mount Liang (liang shan) 
to rebel against the imperial government, who eventually are granted amnesty by the Emperor and sent on campaigns to suppress other local rebel forces. White Faced Gentleman, also known as The Manor of the Cai's (Cai jia zhuang), is a story equivalent in genre to a Hollywood production of a combined genre of crime/gangster and romance. Falling into genre romance, it may be headlined as "heroine doesn't know she is her husband." The story, set in the Song dynasty, is about how Zheng Tianshou, a young man nicknamed as "white faced gentleman" due to his fair complexion, rescues his wife from the kidnappers, Cai Jiquan and his sister Cai Furong, the owners of the Manor of the Cai's. To approach Cai Jiquan, Zheng Tianshou is disguised as a woman. Obsessed with Zheng's beauty, Cai Jiquan relaxes his vigilance and takes liberties with him. Zheng seizes the opportunity to assassinate Cai, but unsuccessfully. Joined by his sworn brothers and fellow outlaws, Lu Zhishen, Li Kui, and Wu Song, he is finally able to defeat the villains and reunite with his wife. In this play, Wen plays Zheng Tianshou in the xiaosheng role category, but when Zheng Tianshou is disguised as a woman to rescue his wife, Wen needs to switch to the dan category. Thus, it is the story that makes Wen's switch plot-wise necessary and politically legitimate.

The success of the jingju adaptation of the widely known Water Margin story that required singing and acting skills of both xiaosheng and dan role categories helped a great deal with Wen's transfer from his assigned xiaosheng role category to his desired dan role category. The début and increasing popularity of the play made Wen an overnight celebrity in the jingju scene: In 1984 alone he did over forty shows. He was eventually allowed to transfer to the dan role category, and thus became the first nandan performer recognized after the Cultural Revolution. Because of the very exceptional nature of the approval, he was also believed to be the "last" nandan performer.

Wen confessed during the interview that White Faced Gentleman was a strategy for his transfer, for White Faced Gentleman created a perfectly justifiable chance for him to showcase his long reserved dan performance capacities and increasingly mature personal style which had evolved from the Zhang school. First of all, he was still in his xiaosheng role category, but playing a young man disguised as a woman in a "play" within a play; in other words, he was not actually transferring to the dan role type officially, but was playing in a dan role according to the needs of the story. According to Wen, Weng and he conceived the idea of adapting this Water Margin story under the overwhelming pressure of the social bias against nandan in the 1980 s, which has more or less continued up to this day. The social bias against cross-gender performance in the PRC, especially male-to-female cross-gender performance is not a sole outcome of the political campaigns to forge proletarian literature and art against bourgeoisie and feudal ideology. In my view, which is shared by Wen himself as well as many other theatre critics and sociologists in the PRC, the pressure that Weng and Wen had felt then was also associated with the influence of Western homophobia. Nandan has always been associated with homosexuality, sassiness, transvestism and sodomy, while homosexuality was for a long time a pathological term in the PRC, considered representative of "the evil of Western civilization," "evil, ugly, anti-human," and "an insult to human dignity," which could "destroy socialist civilization" [4].

While to be a nandan performer by profession means having to take the risk of being suspected to be "perverted" or "abnormal," Wen emphasizes that nandan is "art for art's sake" and that a jingju performer should have the freedom to play whatever role category suits him or her the best. For himself, he believes that he is great dan material, given his vocal and physical attributes. He stands five feet and six inches tall, which is not an ideal height for xiaosheng. He has a smallish face, though rather on the masculine side, a slim build, and narrow and round shoulders, which enable him to transform into a woman with great ease. Although his speaking voice is very deep and masculine, he has a naturally high-pitched falsetto voice, sonorous, strong, with a wide range and "metallic qualities," in Sun Peihong's words, even though he has been a lifelong heavy smoker. His soprano-like falsetto voice and bass-like speaking voice always surprise people, with such a drastic contrast. Given the penetrating power of his falsetto voice, when he sings and speaks while performing jingju, his voice can be transmitted to the last row in a medium sized theatre without the use of microphone and speakers, according to Sun. Due to his vocal strengths, he was chosen to sing behind the scene for the character Cheng Dieyi in the film, Farewell, My Concubine.

Wen reaffirms that a jingju performer should be able to choose a role category based on his or her vocal and physical strengths rather than gender. In fact, before the ban of nandan training, jingju performers were able to learn to perform characters of their own and/or the opposite sex compatible with their vocal and physical strengths. Another major reason for his determined role category transfer was because he had always been drawn to the role category of dan and its glamour culminating at the time of the formation of the Four Great Dan until the 1950s when the Zhang school emerged. Indeed, dan had never been so glamorous in the past till the time of the Four Great Dan, who had sublimated the role category through unprecedented skills and innovations to a level that represents an ideal of poise and beauty in the portrayal of female characters. His creative urges have consistently been fuelled by a desire to create women on stage to achieve the glamour he has seen and desired regardless of all the bias and obstacles he has faced. That desire has a more transgressive nature than ever under the aforementioned circumstances. It has to be clarified, however, that he has never fantasized about being a transvestite. He believes that a real performing artist should be able to distinguish on-stage performance from off-stage life. In fact, he strikes me as such. Nandan, according to him, is unlike a drag queen in cabaret. The common Western perception of nandan as parallel to cross-dressing or transvestism is conceptually incorrect, as female impersonation in jingju is not simply undertaken to mimic a woman, but also to demonstrate through formulated conventions the "feminine" qualities. An experienced spectator's gaze concentrates on how well those qualities are demonstrated, rather than how accurately a man imitates a woman. Therefore, nandan is rather a male construct of women characters, which re-produces the female gender in a male-created theatrical form from the male perspective and, in the sexist, misogynist past, for the male gaze only. I would emphasize here that 
even though he justifies the normality of nandan vigorously in terms of the performance art, he also acknowledges the transgression behind it, largely because nandan nowadays is no longer a practical necessity, since there are many women performing dan very well. Many contemporary female dan performers, known as kundan, have in fact surpassed most of their male predecessors in terms of their overall artistic skill level, according to Lin Ruikang, an interviewee retired from the Ministry of Culture's jingju office. In this sense, since the ban on nandan training and female dominance of the dan role type, nandan has become a form of voluntary transgression rather than the theatrical norm. So, to be a nandan performer is not to "have to" do it anymore, but to "want to" do it. In subsequent interviews in 2012 and 2014, Wen confessed multiple times that he chose dan because he loved this role category, loved creating female characters as a performer, and saw it as a lifelong obsession.

Since and aside from White Faced Gentleman, Wen has also played in leading dan roles in many other plays. Despite his successful transfer, the government did not really lift the ban on nandan. Nowadays nandan training is not officially forbidden anymore, but it is still not widely encouraged, and nandan students are still very rare. There is, however, currently an increasing number of nandan of the younger generations who are actively performing on stage and TV, including Liu Zheng, Liu Bing, Liu Xinran, Yang Lei, Mu Yuandi, Yin Jun, Huang Huang, just to name a few.

\section{ANOTHER REVIVAL}

It is also critically important and necessary to mention the revival of all-female уиеји, as it was banned during the Cultural Revolution. As discussed previously, cross-gender performance as a backward feudalistic product that reveals a distorted gender representation may "ruin" or "uglify" the heroic image of the proletarians.

It is interesting to note that though jingju casts remain largely male-and-female, all-female уиеји quickly revived after the Cultural Revolution. All-female yиеju, which has never been too controversial, has trained a new generation of stars, such as Mao Weitao, who is a woman playing male roles under the xiaosheng role category. She is also currently the President of the prestigious уиејu troupe in the Zhejiang province-“Little Hundred Flowers" Үиејu Company (xiao bai hиа уиеји tuan).

During my interview with Lin Ruikang, a veteran kunqu performing artist and former Deputy Director of Jingju Revitalization Office (zhenxing jingju ban gong shi), Bureau of Arts (yishu ju), at the PRC's Ministry of Culture, she conveys the reasons she has discovered behind the enduring popularity of yиeju's all-female casting. According to her analysis based on the repertoire and style of yиејu, it is a feminine theatrical art form that works best with an all-female cast in narrating romance, which is loved by most women. Yueju fans including those who seek romantic friendship with other women-either performers or fellow fans or amateur performers-and have contributed to creating the norms in the уиеји economy over the years. The initial tone set for the genre has determined the suitability and stability of its all-female status, which has gradually removed male performers from its arena. Moreover, since yиеju audience members and fans have always been mostly female [5], an all-female crew renders the "sisterly" interaction much easier. As Jiang observes about уиеји in Republican Shanghai, “[W]omen's [y]ue opera companies appeared to be pure and clean, with a hint of virtue and chastity... Furthermore, the very absence of male actors backstage was convenient for women patrons, permitting them to move in and out freely and appropriating it as a women's space" [6]. This somehow suggests that the critical promise of all-female yиеju has to do with the systemic failure of heterosexual regimes ever fully to express their own ideals, and in the уиејu scene the failure of heterosexual regimes is a "natural selection" in the aesthetic regime, which has boosted the enduring cross-gender expression, causing the flourishing and revival of all-female casting before as well as after Mao's time.

Having developed from its initial all-male casting, to male-and-female mixed casting, then to all-female in Republican Shanghai, male-and-female during the Cultural Revolution, and finally to the revival of the all-female casting, nowadays yиеju remains primarily all-female. This particular $x i q u$ genre is perfectly compatible with its favourite genre romance and its enduring female-to-male cross-gender casting. Despite the political manipulation of the genre along with its repertoire, making it a propagandistic tool either to promote the liberated image of the Chinese women against feudal patriarchy in the early period of the PRC or to erase femininity from revolutionary heroic plays during the Cultural Revolution, the "queer" aesthetic tradition as a natural choice has eventually survived the state intervention which is largely gender-based. Theatre is not only an isolated regime that rejects political involvement deep within its own system of national identity, but also an epitome to reflect the current reality we live in, where women have achieved more discursive power and the right to voice their need and desires.

\section{The Mainstreaming OF Drag In Popular Media}

Chinese xiqu had nandan performers in many genres in history, such as kunqu (Kun Opera), chuanju (Sichuan Opera), minju (Fujian Opera), qinqiang (Shaanxi Opera), Hebei bangzi (Hebei Opera), and chuju (Hubei Opera), with jingju being the most influential [7]. While nandan was considered the theatrical norm in the past, it is perceived as transgressive in a modern sense. Jingju or xiqu in general demonstrates typicality of gender transgression in its tradition of cross-gender performance and the homoerotic subculture that derives from that theatrical tradition, but it does not mean that the transgression belongs to jingju or xiqu exclusively. In fact, the typicality is also suggestive of a universality of gender transgression which has extended to other aesthetic practices as seen in popular media, entailing a plethora of approaches to gender expressions with a transgressive nature. If a male dancer voluntarily and habitually employs in his performance bodily movements that are perceived by people as feminine, for example, it may be suggestive of an expression of gender transgression (but still the specificity of each case needs to be taken into account). If a man habitually hums the tune of a song exclusively sung by female singers, it may also be considered an expression of gender transgression, even though not to the extent of the extreme behaviour of doing drag, cross-dressing, 
transvestism or even receiving a sex reassignment surgery. One of my interviewees involved in drag performance, Wang Zilin, who is a male in his late 50s, almost always sings or hums songs that are normally sung by women, either at home, or when driving, or at karaoke. He expresses a natural "resistance" to singing "men's songs." Also, he shows a natural resistance to being called "brother" and/or "uncle," as, in his own words, he does not feel comfortable, and he would rather be called "sister." The incongruity between the voluntary, habitual behaviour and the biological gender of the subject suggests the tendency to transgress one's assigned gender. The outer gender-variant expression is always mobilized by the sense of a gendered self relatively stable at least within a certain length of time.

Although jingju has created a relatively safe space for gender transgression, due to the legitimate status in its tradition, when the growing desire for gender transgression cannot be fulfilled due to the lack of proper theatrical training or an accommodating theatrical setting, other forms of gender transgressive aesthetic practices may emerge consciously or unconsciously in lieu of theatrical performance. These practices may include - but are not limited to - drag or gender-ambiguous performance in popular media. Nowadays gender transgression can be seen in many reality talent competitions on TV in the PRC, including "Avenue of Stars" (Xing guang da dao), "Voice of China" (Zhongguo hao shengyin), "So You Think You Can Dance" (Zhongguo hao wudao), "China Has Got Talent" (Zhongguo da ren xiu), and "Drama Contest" (Guo se tian xiang). In these shows, gender transgression does not only take the "extreme" form of cross-dressing; in fact, in most cases gender transgression is represented through crossing traditional gender binaries and subverting gender norms. In "So You Think You Can Dance" in 2014, for example, three male dancers, Li Yang, Whyan Chen, and Shi Sunhao, dance wearing high heels and an outfit that may be considered by many people appropriate only for women. Two other male dancers perform belly dance, which is usually dominated by all females. Another male dancer performs the peacock dance, a popular tribal dance in the Yunnan province of China, which is also exclusively performed by female dancers. It should be noted that none of these competitors is doing drag, or, say, cross-dressed in their performance.

Gender transgression in these performances may go by unnoticed or undervalued because the non-normative style, elements or measures employed in them are often perceived as a mere publicity gimmick to attract attention, rather than a gender alternative expression of the subject. Gender transgression is more manifest in drag shows, which draw more attention and generate more debates over the Internet. Among the gender-creative singing competitors, Huo Zun (1990-) has extended his singing career into the involvement of nandan performance in jingju. He gained fame in the singing competition, "Asian Wave" (Sheng dong yazhou), and became popular nationwide by winning the first season of "Sing My Song “ (Zhongguo hao gequ), a competition for songwriters to sing their own compositions. His original Rolled-up Pearl Curtain (Zhu juan lian), a song marked by its poetic lyrics, gentility and delicacy and his gender-ambiguous rendition partially using falsetto voice, was a mega-hit in the PRC. He went on to performing in the
China Central Television's (CCTV) Chinese New Year's Eve Gala and winning a main prize in the Tianjin Satellite Channel Drama Contest Season One (Guo se tian xiang) by playing a nandan in jingju, singing Time To Say Goodbye in falsetto voice with one of China's highly acclaimed tenors, Mo Hualun. With his portrayal of women, his grace and voice that won the unanimous praise by professionals, he was awarded the title "2014 Drama King" [8].

Although he has been accepted and loved by mainstream society, Huo Zun is not yet the most successful singer doing drag in the PRC. Li Yugang (1978-), for example, is a "grass-roots" independent drag artist who has become extremely successful in the PRC. He launched his vocal concert at the Sydney Opera House in 2009 dressed as a classical Chinese beauty [9], and also performed in drag at the CCTV's Chinese New Year's Eve Gala (chun wan) in 2012 and 2013. In 2009, he was accepted to the prestigious China Opera and Dance Drama Company (CODDC) (Zhongguo geju wuju yuan) for a permanent position after his rise to stardom through participating in the CCTV's "Avenue of Stars," a popular Chinese talent show similar to "American Idol" [10]. CODDC hosted a press conference for the appointment, witnessed by some of the nation's top celebrities, who had been invited as special guests to the event. He is now entitled China's State First-Class Performing Artist (guojia yiji yanyuan).

Although he is constantly mentioned by critics, media and his fans in the same breath with Mei Lanfang, he is not a nandan performer of jingju, nor has he ever trained to be one, as he primarily performs Chinese folk songs and dance. He has, however, largely integrated jingju elements into his song-and-dance performance, such as the musical style, bodily movements, and the headdress and costumes for dan in jingju. In addition, some of his shows reference such jingju plays as Farewell, My Concubine and The Drunken Beauty (guifei zui jiu). He also performs excerpts from the newly created symphonic historical jingju play, The Concubine of the Tang Dynasty (da tang guifei). The effort he makes to "implicate" the nandan art of jingju in his performance is somehow a strategy many drag artists would utilize to legitimatize and normalize their art. This has been confirmed by two drag queens I interviewed in Beijing, Li Meimei and Zhang Bing, both of whom have at some point employed jingju elements in their shows or compared themselves to nandan. In Li Mei's own words, "What we do [drag] is nothing shameful. We are just like nandan in jingju; it is a national treasure, our cultural essence, and our national pride. "Another interviewee who frequents drag clubs in Beijing, Yan Lang, believes that while in Chinese tradition, a man's feminine beauty is always considered the ideal, young women and especially gay men nowadays seem to admire muscularity and masculinity of men over sissy boys. He claims that it is under Western influences. Yan started his career as a photographer and is now an actor and model who has appeared in several TV commercials.

Li's success is definitely not an accidental singular case, given the numerous supportive factors involved. What I find most interesting in the Li Yugang phenomenon is the drastic contrast between his rise to mainstream stardom doing drag with the support of the PRC's mainstream media (including but not limited to the CCTV) along with the connivance of 
the state government and the fear of discrimination he underwent during the earlier stages of his drag career [11]. The dramatic dilemma that $\mathrm{Li}$ has typically experienced perhaps conveys the paradoxical attitude of society. On the one hand, the making of a social taboo out of nandan over time has courted homophobia and femmophobia among the masses, and hence all those institutional obstacles for its legitimacy and normalization; on the other hand, the increasing popularity of drag on mainstream media is an outcome of a consumer economy that accentuates demands of audiences as consumers within the very terms of marketability of the visual products. Unlike Western cultures, Chinese (or East Asian) gender aesthetic tradition always favour young scholarly men's feminine beauty over hyper-masculinity, which has roots in the worship of the mother figure in Chinese folk culture as well as in Confucianism which places emphasis on intellectual achievements and which despises physicality [12]. Hence we see nearly all male protagonists in classical Chinese literature with the gentility, delicacy, and other feminine qualities, such as Jia Baoyu in Dream of the Red Chamber, one of the four greatest classical Chinese novels [13].

\section{CONCLUSION}

The revival of nandan in jingju and all-female yueju and the increasing popularity of drag in the PRC can all find their roots in the long yin-oriented aesthetic tradition, while the current paradox is perhaps suggestive of a transgressive pleasure that both the performer and the spectator experience simultaneously in doing and watching the cross-gender reiteration - and also an insubordination-of the "original" other. In other words, the transgressive pleasure not only lies in the theatricality of "doing" a different gender while maintaining the consciousness of the subject "being" a different gender; it also stems from the process of witnessing the dialectical correlation between the truth of the illusory and the illusory of the truth.

As several interviewees, including Sun, Wen, Yan, and Zhang, all agree, we are living in a new era featured by the Internet, smart phones, social networking, and information explosion, and we are not closed to the outside anymore. Finding "many, many others like myself" has released many people's forbidden or suppressed desires. In this sense, as Wen concludes, being a nandan or doing drag is not simply a personal hobby or a chosen career, but a way to express non-conforming gender desires. "You have to want to be a woman on stage to do it," he claims. In this sense, the revival of the old tradition is not really a "revival," but a rediscovery of one's gendered self.

The process of witnessing of the spectator is also a kind of participation or "complicity" in the gender-transgressive activity of the performer; the performer and the spectator co-exist, inspire, stimulate, and validate one another. While nandan in jingju requires much performance technique and stylized conventions in "doing" a gender, non-theatrical cross-gender aesthetic activities that do not require as much can go mainstream may underline a more realistic, collective view on a created gendered reality by destructing dominant gender paradigms. The popular reception of such transgressive expressions in the performance art as demonstrated by the high audience rating implies a collective "complicit" inclination rather than massive hostility.

\section{ACKNOWLEDGMENT}

Without the support of the Social Sciences and Humanities Research Council (SSHRC), this paper would have been impossible.

Also, special thanks to Dr. Helen Leung, the supervisor of my doctoral thesis, as well as Drs. Elizabeth Wichmann-Walczak, Peter Dickinson, Kate Swatek, and Veronica Strong-Boag. And thanks to all my interviewees in China.

\section{INTERVIEWS}

Li, Meimei, Beijing, PRC, 2003

Liu, Bing, Beijing, PRC, April 2012 and May 2014

Lin, Ruikang, Beijing, PRC, April 2012

2014

Sun, Peihong, Beijing, PRC, April 2012 and April-May

Wang, Zilin, Vancouver, BC, Canada, July-August 2010, May 2014, July 2015 and June 2016

Wen, Ruhua, Beijing, PRC, April 2012 and April-May 2014

Yan, Lang, Beijing, PRC, April 2014

Zhang, Bing, Beijing, PRC, 2003

\section{REFERENCES}

[1] S. Liu, "Theatre reform as censorship: censoring traditional theatre in China in the early 1950s," Theatre Journal, vol. 61, no. 3, pp. 387-91, 2009.

[2] J. Riley, Chinese Theatre and the Actor in Performance, Cambridge University Press, 1997.

[3] E. Wichmann-Walczak, "Tradition and innovation in contemporary Beijing opera performance,” The Drama Review, pp 146-178, Spring 1990

[4] F. Ruan, M.D. and Y. Tsai, "Male homosexuality in contemporary mainland China," Archives of Sexual Behavior, vol. 17, no. 2, 1988.

[5] J. Jiang. Women playing men: Same-sex relations in republican Shanghai. Harvard-Yenching Working Paper Series. [Online]. Available:

http://www.harvard-yenching.org/sites/harvard-yenching.org/files/feat urefiles/Jiang\%20Jin_Women\%20Playing\%20Men.pdf

[6] J. Jiang. Women playing men: Same-sex relations in republican Shanghai. Harvard-Yenching Working Paper Series. [Online]. Available:

http://www.harvard-yenching.org/sites/harvard-yenching.org/files/feat urefiles/Jiang\%20Jin_Women\%20Playing\%20Men.pdf

[7] G. Wei. (1997). Jingju nandan manyi (On Nandan of Jingju). Da wutai (Great Stage). [Online]. Available: http://www.cnki.com.cn/Article/CJFDTotal-DWUT199703004.htm

[8] “'Guo se' Huo Zun duo guan, 'Hao ge qu' hou zai cheng wang” (Huo Zun won championship in Drama Contest, another victory after "Sing My Song"). Sina Entertainment. [Online]. Available: http://ent.sina.com.cn/j/m/2014-04-20/11214129819.shtml

[9] Li Yugang's rendition of The Drunken Concubine intoxicates Sydney; solo concert spreads a perfect Chinese scroll painting). Sina Entertainment. [Online]. Available: http://ent.sina.com.cn/j/2009-07-29/07522629275.shtml

[10] S. Yang. Li Yugang joins China Opera and Dance Drama Company and ends 'drifting'). Xinlang yule (Sina Entertainment). [Online]. Available: http://ent.sina.com.cn/j/2009-02-23/22502388515.shtml

[11] L. Gao, Li Yugang: impersonating women by mistake - the story of his unknown drag career. Xinwen Chenbao (News Morning Post). [Online]. http://ent.sina.com.cn/j/2009-11-19/07402775334.shtml

[12] P. Yi, Zhongguo Shenmei Wenhua Minzu Xing de Xiandai Renleixue1 Yanjiu (Modern Anthropological Research on the National Traits of 
the Chinese Aesthetic Culture). Beijing: Zhongguo shehui chubanshe, 2012.

[13] L. Edwards, "Jia Baoyu and essential feminine purity," Journal of the Oriental Society of Australia, pp. 36-47, 1988-89.

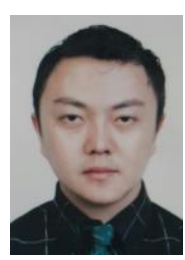

Huai Bao a Chinese-born Canadian Citizen, received his $\mathrm{Ph} . \mathrm{D}$. in gender studies/east Asian studies at Simon Fraser University in British Columbia, Canada, in 2015. He went on to conducting postdoctoral research at the University of Toronto in 2016. He was the recipient of the SSHRC Doctoral Scholarship for 2013-2015 and the recipient of the SSHRC postdoctoral research fellowship for 2016-2018. The author of two best selling books in China, he has had 16 peer-reviewed scholarly articles accepted for publication in Europe, Canada, USA and China as of June 2016
His research interests include sexuality and gender politics in contemporary Chinese and East Asian societies, critical race theory, Asian diaspora and memory studies, Asian religions and spiritual trends, the evolution of the belief system in China, and Asian performance studies.

Dr. Bao is a member of such organizations as IFTR, CPSC and WCCA. 